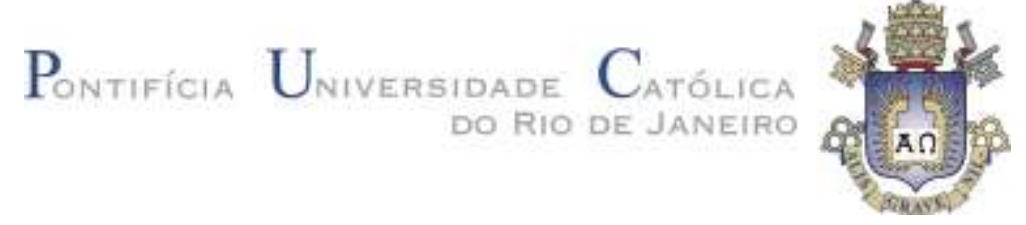

Marcelo Gomes Farinhas

\title{
Análise da Falha de um Sonotrodo para Corte de Borracha
}

Dissertação de Mestrado

Dissertação apresentada como requisito parcial para obtenção do grau de Mestre pelo Programa de Pós-Graduação em Engenharia de Materiais e de Processos Químicos e Metalúrgicos do Departamento de Engenharia Química e de Materiais do Centro Técnico e Científico da PUCRio.

Orientador: Prof. Marcos Venicius Soares Pereira 
Marcelo Gomes Farinhas Análise da Falha de um Sonotrodo Para Corte de Borracha

Dissertação apresentada como requisito parcial para obtenção do grau de Mestre pelo Programa de Pós-Graduação em Engenharia de Materiais e de Processos Químicos e Metalúrgicos do Departamento de Engenharia Química e de Materiais do Centro Técnico e Científico da PUCRio. Aprovada pela comissão Examinadora abaixo assinada.

Prof. Marcos Venicius Soares Pereira

Orientador e Presidente

Departamento de Engenharia Química e de Materiais - PUC Rio

Prof. Fathi Aref Ibrahim Darwish Universidade Federal Fluminense - UFF

Dr. Arnaldo Freitas Camarão SAE Brasil

Prof. José Eugenio Leal Coordenador Setorial de Pós-Graduação do Centro Técnico Científico da PUC-Rio

Rio de Janeiro, 04 de setembro de 2015. 
Todos os direitos reservados. É proibida a reprodução total ou parcial do trabalho sem autorização do autor, do orientador e da universidade.

\section{Marcelo Gomes Farinhas}

Graduou-se em engenharia elétrica na Universidade Veiga de Almeida, no Rio de Janeiro em 1991. Atuou como PCP em indústria de fabricação de Material Elétrico e analista de contratos de fornecimento de cubículos e quadros elétricos na empresa Westinghouse do Brasil, Chefe de manutenção Central em indústria de fabricação de pneus empresa Michelin e professor de Eletrotécnica, Automação e Controle na Fundação de Apoio a Escola Técnica e no Instituto Federal do Rio de Janeiro IFRJ campus Paracambi.

Ficha Catalográfica

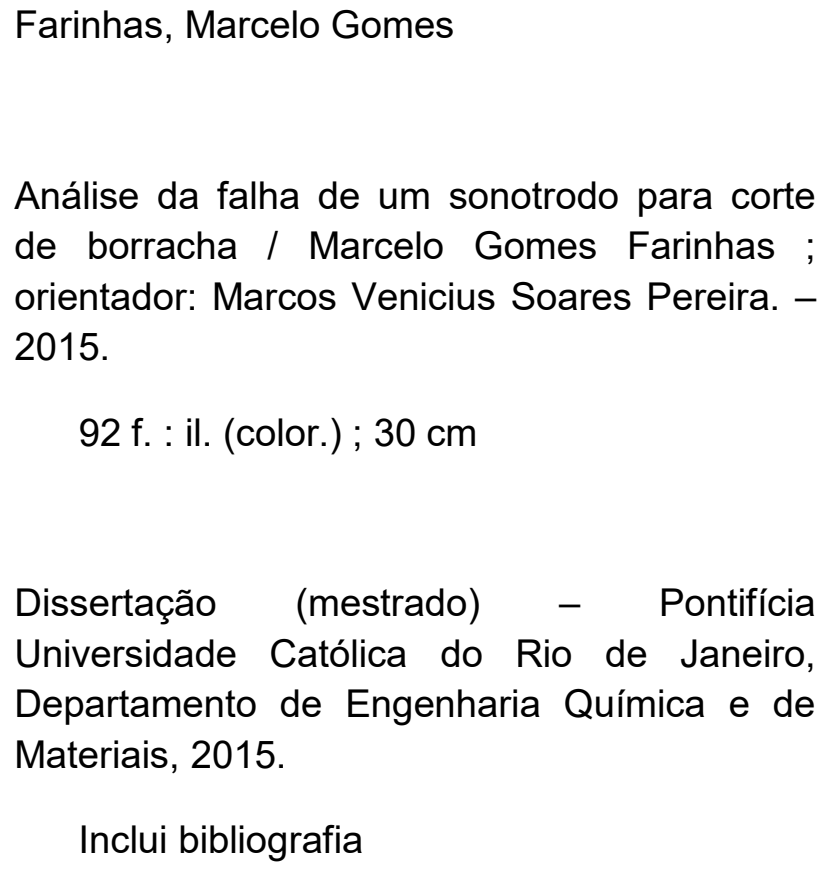


A minha esposa Eliane, pelo amor e carinho;

As minhas filhas amadas Priscilla e Giselle A minha mãe Maria do Carmo Ao meu pai Manuel (in memoriam) Aos meus sogros Genésio e Jovina (in memoriam) 


\section{Agradecimentos}

A Deus.

Aos meus pais pela educação.

Ao professor Marcos Venicius Soares Pereira pelas orientações providenciais para a realização deste trabalho.

À CNPq, ao Instituto Federal do estado do Rio de Janeiro (IFRJ) e a Pontifícia Universidade Católica do estado do Rio de Janeiro (PUC-Rio) pelos auxílios concedidos, sem os quais este trabalho não poderia ter sido realizado.

A todos os professores e funcionários da PUC pelo apoio à pesquisa em especial ao professor Sidnei Paciornik do laboratório de imagens da PUC-Rio.

Aos Meus colegas da PUC-Rio.

Aos professores que participaram da Comissão Examinadora.

Ao Prof. Alzemiro da Empresa Miro Maquinas pelo apoio na fabricação dos corpos de prova sem os quais não teríamos conseguido realizar os ensaios deste trabalho.

Ao Prof. Cabral da empresa JFC que prestou assistência com os materiais indispensáveis a concretização desta pesquisa.

A Michelin pelo apoio e liberação de horário para a realização do curso de Mestrado.

Aos colegas da Michelin, Francisco, Marcelo Cardozo, Adacyl, que colaboraram ativamente na coleta de material e suporte para a fase experimental deste trabalho.

A todos os amigos e familiares que de uma forma ou de outra me ajudaram ou me estimularam na realização desta empreitada. 


\section{Resumo}

Farinhas, Marcelo Gomes; Pereira, Marcos Venicius Soares. Analise da Falha de um Sonotrodo para corte de Borracha. Rio de janeiro, 2015. 92p. Dissertação de Mestrado - Departamento de Engenharia Química e de Materiais, Pontifícia Universidade Católica do Rio de Janeiro.

Os processos industriais de uma maneira geral são compostos de várias etapas que promovem a transformação de materiais, seja na sua forma primária, ou na forma de subprodutos, que vão posteriormente formar o produto final. Neste contexto, na indústria fabricação de pneus, existe uma etapa bastante específica que é o corte de borracha, etapa esta, que pode ser realizada de várias formas e técnicas sendo que uma delas, é o corte por ultrassom. Apesar do corte por ultrassom ser eficiente e proporcionar ao material um acabamento nas superfícies superior aos demais, os sistemas de corte por este método apresentam fraturas excessivas do componente que realiza o corte, chamado de sonotrodo. Neste trabalho, foram investigadas algumas das causas possíveis (causas raízes) para as falhas apresentadas pelos sonotrodos. O estudo envolveu a análise química qualitativa do material, a análise de tensões utilizando o método de elementos finitos, ensaios mecanográficos e caracterização mecânica do material. Os resultados obtidos permitiram a identificação do mecanismo de dano acumulado no componente durante sua vida em serviço, permitindo a indicação de possíveis causas raiz que levam o sonotrodo a falhar de maneira prematura.

\section{Palavras-Chave}

Corte; Ultrassom; Aço para lâminas; Material Polimérico. 


\section{Abstract}

Farinhas, Marcelo Gomes; Pereira, Marcos Venicius Soares (Advisor). Failure Analysis of a Sonotrode For Rubber Cut. Rio de janeiro, 2015. 92p. MSc. Dissertation - Departamento de Engenharia Química e de Materiais, Pontifícia Universidade Católica do Rio de Janeiro.

Industrial processes generally are comprised of several steps that promote the transformation of materials, whether in their primary form, or as by-products, which will subsequently form the final product. In this context, the tire manufacturing industry, there is a very specific step is the cutting of rubber; this step can be performed in various ways and techniques one of which is the cutting by ultrasound. Although efficient cutting and the cut material presenting a finish of the cut surfaces higher than the other cutting systems ultrasound have excessive fractures component that performs cutting, called sonotrode. In this study, we investigated some of the possible (root cause) for failures made by sonotrode. The study involved a qualitative chemical analysis of the material, stress analysis using the finite element method, metallographic tests and mechanical characterization of the material. The results obtained allowed the identification of the accumulated damage mechanism in the component during its service life, allowing indication of possible root because that lead the sonotrode to fail prematurely.

\section{Keywords}

Cut; Ultrasound; Blade Steel; Polymer Material. 


\section{Sumário}

1. Introdução

2. Revisão Bibliográfica 18

$2.1 \mathrm{O}$ ultrassom 18

2.1.1 Frequências Audíveis e inaudíveis $\quad 18$

2.1.2 O Ouvido Humano 19

2.1.3 Princípios das Vibrações Mecânicas 19

2.1.4 Frequência Natural 23

2.1.5 Amortecimento ou Atrito Interno 25

2.1.6 Princípios da tecnologia ultrassónica de potência 27

2.1.7 Sintonia de Sonotrodos 28

2.1.8 O Dispositivo vibrante para corte por Ultrassom 29

2.1.9 Sonotrodo defeituoso 30

2.2. Fluorescência de Raios $X \quad 30$

2.2.1 Dados Qualitativos XRF 34

2.2.2 Dados quantitativos XRF: calibrações e quantificação 34

2.2.3 Dados Semi-quantitativos XRF 35

2.3 Teoria de Elementos Finitos 36

2.3.1 O Software ANSYS $\quad 37$

2.3.2 O Critério de Falha de Von Misses 38

2.3.3 Concentração de Tensão 41

2.3.4 Fator de concentração de Tensão para trincas elípticas 42

2.4 O Ensaio de Tração 43

2.5 O Ensaio de Impacto 44

2.5.1 Tipos de ensaios de impacto 45

2.6 Ensaio de dureza 46

2.6.1 Dureza Rockwell 47

$\begin{array}{ll}2.7 \text { Microestrutura dos aços } & 47\end{array}$

2.7.1 Microestrutura e fases 48

$\begin{array}{ll}\text { 2.7.2 Martensita } & 49\end{array}$ 
2.8 Fadiga 50

2.8.1 Curva S-N 51

2.8.2 UHCF - Fadiga de Ultra Alto Ciclo 51

2.8.3 UHCF - Efeito da Frequência 52

3 Material e procedimento experimental 53

3.1 Material 53

3.2 Simulações pelo Método de Elementos Finitos 55

3.2.1 Geometria e posição de retirada dos corpos de prova 55

3.2.2 Corpos de prova para ensaio Tração 57

3.2.3 Corpo de prova para ensaio Charpy 58

3.3 Ensaios com Liquido Penetrante 58

3.4 Ensaios de Tração 61

3.5 Ensaios de Charpy 61

3.6 Caracterização da Microestrutura 61

3.7 Ensaios de Dureza Rockwell 62

$\begin{array}{ll}3.8 \text { Fractografia } & 63\end{array}$

4 Apresentação e discussão dos resultados $\quad 64$

4.1 Resultados da Analise de XRF - Fluorescência de Raios X. 64

4.2 Resultados da Simulação por Elementos Finitos 65

4.2.1 Cálculo do Concentrador de Tensão 71

4.3 Resultados do ensaio de Líquidos Penetrantes 71

4.4 Resultados do ensaio de Tração 73

$\begin{array}{ll}4.5 \text { Resultados do ensaio de Charpy } & 74\end{array}$

4.6 Resultados do ensaio de Dureza $\quad 75$

4.7 Resultados da Análise de Microestrutura 76

$\begin{array}{ll}4.8 \text { Resultados Análise Fractográfica } & 79\end{array}$

$\begin{array}{ll}5 \text { Conclusão } & 87\end{array}$

6 Referências bibliográficas 90 


\section{Lista de figuras}

Figura 1- Campo de audibilidade das vibrações Mecânicas 18

Figura 2- O ouvido humano 19

Figura 3- Esquema representativo da frequência natural dos Materiais 21

Figura 4- Movimento harmônico 21

Figura 5- As componentes do movimento harmônico 22

Figura 6 - Amortecimento $\quad 24$

Figura 7 - Histerese 26

Figura 8 - Conjunto Acústico 27

Figura 9 - Curva de impedância em função da frequência de um Transdutor 28

Figura 10 - Técnicas de usinagem para ajuste da frequência de operação dos sonotrodos $\quad 28$

Figura 11 - Conjunto de corte por ultrassom 29

Figura 12 - Foto de um Sonotodo tipo Faca - Trinca, Utilizado para este estudo, indicada pelo circulo vermelho 30

Figura 13 - Processo de fluorescência 32

Figura 14 - Fluxo de análise de um sonotrodo utilizando o software ANSYS

Figura 15 - Circula de Mohr 40

Figura 16 - Tensor Cauchy 41

Figura 16- A - Parâmetros de geometria de uma trinca elíptica Ideal

Figura 17 - Desenho esquemático de um corpo de prova submetido à carga de tração

Figura 18 - Maquina para ensaio de impacto e os dois tipos de ensaios Charpy e Izod 
Figura 18-A - Parâmetros que influenciam uma microestrutura

Figura 18-B - Organização dos átomos de ferro em função

da temperatura

Figura 18-C - Diagrama ferro x carbono

Figura 18-D - Microestrutura Martensita

Figura 18-E - Curva S-N típica

Figura 19 - Desenho dimensional de um sonotrodo

Figura 20 - Ensaio de Fluorescência de raio $X$

Figura 21 - Retirada de espécimes no sentido da laminação

56

Figura 22 - Desenho esquemático da retirada dos espécimes da amostra da faca

Figura 23 - Geometria dos corpos de prova para o ensaio de Tração

Figura 24 - Geometria dos corpos de prova para o ensaio de Charpy

Figura 25 - Revelação dos defeitos com ensaio de líquidos Penetrantes

Figura 26 - Ensaio de líquidos penetrantes na faca sonotrodo

Figura 27 - Resultados da análise de XRF em espectrômetro da Bruker

Figura 28 - Sólido importado para o ANSYS

Figura 29 - Malha após a aplicação do comando Mesh

Figura 30 - Aplicação de apoio fixo na base do sonotrodo

Figura 31 - Aplicação de Força de $100 \mathrm{~N}$ na face lado A do sonotrodo

Figura 32 - Aplicação de Força de $100 \mathrm{~N}$ na face lado B do sonotrodo

Figura 33 - Resultado a simulação da ciclagem pelo critério de falha de Von Mises no ANSYS usando o módulo estrutural Estático

Figura 34 - Catálogo do Aço SAE 8550

Figura 35 - Corpos de prova retirados de um sonotrodo após 
ensaio de liquido penetrante

Figura 36 - Gráfico de tensão x deformação do ensaio de tração 73

Figura 37- Microestrutura do aço 8550 analise em microscópio óptico 77

Figura 38 - Microestrutura do aço 8550 analise em MEV 300x C4 77

Figura 39- Microestrutura do aço 8550 analise em MEV 1500x C4 78

Figura 40 - Microestrutura do aço 8550 analise em MEV 50 x C5

Área do entalhe e inicio da fratura

78

Figura 41 - Microestrutura do aço 8550 analise em MEV 1800x C5 79

Figura 42 - Medida do tamanho da trinca em microscópio Óptico Zeiss

Figura 43 - Região da trinca retirada da faca sonotrodo para realizar a abertura da trinca

Figura 44 - Imagem da amostra após a abertura da trinca pré-existente

Figura 45 - Inicio da fratura na região superior $50 x$

Figura 46 - Início da Fratura 16x

Figura 47 - Meio da fratura $115 x$

84

Figura 48 - Final da fratura $115 x$

85

Figura 49 - Transição final da fratura x rompimento da amostra 


\section{Lista de tabela}

Tabela 1

Energias (em keV) das transições $\mathrm{K}$ dos elementos de $23<Z<30$

Tabela 2

Composição química característica do Aço estrutural SAE 8550

Tabela 3

Medidas relativas ao modelo importado para o Software Ansys

Tabela 4

Resultados de número de malhas e nós

Tabela 5

Resultados do ensaio de tração

Tabela 6

Resultados dos ensaios de Charpy

74

Tabela 7

Resultados dos ensaios de Dureza 


\section{Lista de equações}

Equação 1

Deslocamento de uma onda senoidal no tempo

Equação 2

Velocidade de uma onda senoidal no tempo

Equação 3

Aceleração de uma onda senoidal no tempo

Equação 4

Velocidade angular para os materiais naturais

Equação 5

Impedância acústica dos materiais

Equação 6

Frequência Natural dos materiais

Equação 7

Amortecimento

Equação 8

Integral de volume Método de elementos finitos

Equação 9

Volume total baseado no somatório dos volumes finitos simples

Equação 10

Tensor Tensão de Cauchy

Equação 11

Matriz do tensor tensão de Cauchy

Equação 11-A

Concentrador de tensão

Equação 11-B

Equação de Inglis

Equação 12

Média estatística

Equação 13

Desvio Padrão estatístico 